\title{
$\angle S$ Research Suare \\ Procalcitonin is a Prognosis Biomarker in Late Onset Neonatal Sepsis: A Pilot Study
}

\section{Valerie Ruetsch}

Assistance Publique - Hopitaux de Paris

Simon Barreault

Assistance Publique - Hopitaux de Paris

Nolwenn Le Sache

Assistance Publique - Hopitaux de Paris

Pierre Tissieres ( $\nabla$ pierre.tissieres@aphp.fr)

University Hospital Paris South https://orcid.org/0000-0001-5423-5532

\section{Research Article}

Keywords: PCT, prognosis, neonatal sepsis, LONS, mortality

Posted Date: August 31st, 2021

DOl: https://doi.org/10.21203/rs.3.rs-822579/v1

License: (9) This work is licensed under a Creative Commons Attribution 4.0 International License. Read Full License 


\section{Abstract}

Background. Neonatal sepsis contributes substantially to neonatal morbidity and mortality. Procalcitonin (PCT) is a recognized biomarker for the diagnosis of late-onset neonatal sepsis (LONS), however, little is known about the prognosis value of PCT in LONS. This study aims at assessing PCT value as a prognosis biomarker in preterm infants with LONS.

Methods. Retrospective single center observational cohort. All premature infants (less than 32 weeks of gestational age) with LONS admitted in a tertiary neonatal intensive care unit.

Discussion. Among the 59 preterm infants included in the analysis, 48 survived (81.4\%, 48/59). Deceased patients had a significantly lower gestational age $(p=0,025)$ and weight $(p=0,016)$ at the time of LONS diagnosis. Although PCT values were not different between both groups at the time of LONS diagnosis, it was more elevated during the first 24 hours in deceased patients $(p=0,041)$. Accuracy of PCT for LONS prognosis ranged from 0.70 to 0.82 of area under the curve on reciever operating characteristics curves. Optimal PCT cut-off values at LONS diagnosis was $8,92 \mu \mathrm{g} / \mathrm{L}$ (Youden's $\mathrm{J}$ index 0.53), $15.75 \mu \mathrm{g} / \mathrm{L}$ for PCT values during the first 24 hours ( $\mathrm{J}$ index 0.56 ), and $6.74 \mu \mathrm{g} / \mathrm{L}$ between 24 and 48 hours after diagnosis ( $\mathrm{J}$ index 0.54 ). The estimated survival probability at day 60 was above $95 \%$ for patient with a PCT value at sepsis diagnosis under $8,9 \mu \mathrm{g} / \mathrm{L}$ and less than $45 \%$ if higher $(p<0.0001)$.

Conclusion. A PCT value $>8.92 \mu \mathrm{g} / \mathrm{L}$ obtained at LONS diagnosis suspicion seems to be a good prognosis biomarker.

\section{What Is Known:}

- Procalcitonin (PCT) is a recognized biomarkers of 28-days mortality in critically ill adults with septic shock and trauma.

- Failure to have decreased in PCT in the first days of critical care is associated with increase mortality.

\section{What is new:}

- Hereby, we show that PCT has a prognosis value in premature infants with late-onset neonatal sepsis.

- Procalcitonin value $>8.92 \mu \mathrm{g} / \mathrm{L}$ at LONS diagnosis is associated with an increase 60 -days mortality.

\section{Introduction}

Neonatal sepsis is defined as a systemic infection occurring in the first 28 days of life, with early-onset neonatal sepsis (EONS) occurring within 72 hours after birth and late-onset neonatal sepsis (LONS) thereafter. The incidence of LONS ranges between 0.6 to $27.6 \%$ according to birth weight (BW) and gestational age (GA) [1-4]. Several other neonatal factors such as the presence of congenital 
malformations, mechanical ventilation, administration of total parental nutrition, use of central venous catheter are identified additional risk factors for LONS [5-6]. Gram-positive bacteria, dominated by coagulase-negative staphylococci (CoNS), are being the most frequently encountered pathogen, followed by Gram-negative enterobacteria and fungi which are known to induce more severe clinical manifestations, with higher mortality [7-8]. Due to the poor diagnosis specificity of clinical symptoms, biological biomarkers of sepsis diagnosis are increasingly used [9-10]. Procalcitonin (PCT) is a recognized biomarker with high sensitivity and specificity for the diagnosis of LONS [11]. Currently, PCT has the highest reported negative predictive value (87-100\%) of all established biomarkers for severe invasive bacterial infections in neonates [12-13]. Prognostic value of PCT is recognized in adults with sepsis and septic shock but has not been assessed in neonatal sepsis [14] The aim of this study is to assess PCT as a prognosis biomarker in preterm with LONS admitted to NICU.

\section{Methods}

Retrospective study conducted between January 1st, 2015 and December 31st, 2018 in the neonatal intensive care unit of the AP-HP Paris-Saclay University, Bicêtre Hospital, Le Kremlin-Bicêtre, France. Patients were identified in a prospectively maintained healthcare-associated infection (HAI) surveillance program database. Data were retrieved from the patients' electronic medical records. All neonates under 32 weeks of GA hospitalized with LONS were eligible. Infection was defined according to the Center for Disease Control criterion, as presence of pathogenic organism isolated from one blood culture or clinical infection with two commensal-germ positive blood culture [26]. Neonates who underwent surgery, neonates with necrotizing enterocolitis, and those who previously received antibiotics for EONS were excluded. In order to reduce the survivor bias, infants deceased before day 5 after LONS diagnosis were excluded. The primary endpoint was 60-days mortality. The study (French study classification: MR004) was approved by the local IRB and French Data Protection Authority (CNIL number: 271813) waiving the need of written consent. All legal representatives were informed and could refuse to participate at any time. Patients' records were reviewed to collect the following data on a standardized form: GA, gender, birth weight, mode of delivery, antenatal steroids, postnatal age, and weight at the time of LONS diagnosis. Clinical parameters, respiratory support modalities, use of vasopressors, vascular filling, serum lactate, microbiologic identification, antimicrobial therapy were obtained. Procalcitonin was measured (Elecsys $\rightarrow$ BRAHMS Procalcitonin (PCT) test, Roche Diagnostics, Indianapolis, IN) at sepsis diagnosis time as part of the standard sepsis workup (incl. blood cell count, hemoculture, PCT), and during the following three days ( $\mathrm{HO}$ to $\mathrm{H} 24, \mathrm{H} 24$ to $\mathrm{H} 48, \mathrm{H} 48$ to $\mathrm{H} 72$ ). Sepsis diagnosis time was considered as the time LONS diagnosis suspicion was established and initial biological workup performed. If no PCT assay was available within 48 hours, patients were excluded from the analysis.

Statistical analysis was performed using Easymedstat (EasyMedStat, Levallois-Perret, France). Quantitative variables were described as median and quartiles. Qualitative variables were expressed as percentages and $95 \%$ confidence interval $(95 \% \mathrm{Cl})$. The unpaired Student's $t$-test and the Mann-Whitney test were used to compare age and laboratory variables. Categorial variables were compared with the chisquare $(\mathrm{X} 2)$ or the Fisher exact test. The predictive value of PCT for mortality was assessed using 
Receiver-Operating Characteristics (ROC) curves, area under the curve (AUC) calculated. Youden's J index was calculated to find the best discriminatory cut-off value. Kaplan-Meier survival curves were plotted, and log rank test performed. Hazard ratio (HR) were subsequently calculated. A $p$ value $<0.05$ was considered as significant.

\section{Results}

Out of 689 premature infants hospitalized during the study period, 251 were identified in the HAI surveillance database $(36.4 \%, 251 / 689)$ (Fig. 1). One hundred and sixty-one patients were excluded. Among the remaining 90 premature infants with LONS, 31 were excluded for missing data on PCT kinetics. A total of 59 preterm were included in the analysis, of whom 48 were alive at day $60(81,4 \%$, 48/59). Patients' characteristics are displayed in Table 1. Deceased patients had a significantly lower GA (28 weeks of GA [27-30] vs. 30 [29-32], $p=0,025$ ) and weight (820 grams [730-1065] vs. 1072,5 [850$1320], p=0,016)$ at the time of LONS diagnosis than survivors. No statistically significant difference was found for clinical symptoms nor vascular filling. Deceased patients required more invasive mechanical ventilation $(p<0.001)$ and vasopressors such as norepinephrine $(p<0.001)$ than survivors. Gram-positive bacteria were identified in 43 patients $(73 \%, 43 / 59)$ with CoNS found in $32(74 \%, 32 / 43)$ (Table 1$)$. The proportion of LONS caused by CoNS were significantly higher in survivors $(63 \%$ vs. $18 \% p=0,016)$ whereas LONS caused by Enterobacter cloacae complex was more frequently found in deceased ones ( $46 \%$ vs. $12 \%, p=0,023)$. 
Table 1

Patients' characteristics according to 60-days mortality.

\begin{tabular}{|c|c|c|c|}
\hline & $\begin{array}{l}\text { Survivors } \\
(n=48)\end{array}$ & $\begin{array}{l}\text { Deceased } \\
(n=11)\end{array}$ & $p$ value \\
\hline Gender Male, n (\%) & $26(54)$ & $5(45)$ & 0.74 \\
\hline Term of birth, weeks & $28[26-30]$ & 27 [26-29] & 0,053 \\
\hline Birthweight, grams & 965 [830-1230] & 790 [760-1040] & 0,042 \\
\hline \multicolumn{4}{|l|}{ Mode of delivery } \\
\hline Spontaneous vaginal & $16(33)$ & $6(55)$ & 0,23 \\
\hline Primary caesarean section & $3(6)$ & 0 & 0,08 \\
\hline Emergency caesarean & $29(60)$ & $5(45)$ & 0,4 \\
\hline \multicolumn{4}{|l|}{ Time of LONS } \\
\hline days & $8[5-11]$ & $8[6-14]$ & 0,78 \\
\hline Postmenstrual age, weeks & $30[29-32]$ & 28 [27-30] & 0,025 \\
\hline \multicolumn{4}{|l|}{ Pathogens } \\
\hline CoNS & $30(63)$ & $2(18)$ & 0,016 \\
\hline Staphylococcus aureus & $9(19)$ & $3(27)$ & 0,54 \\
\hline Escherichia coli & $3(6)$ & $1(9)$ & 0,75 \\
\hline Enterobacter cloacae complex & $6(12)$ & $5(46)$ & 0,023 \\
\hline Klebsiella pneumoniae & $0(0)$ & $1(9)$ & - \\
\hline \multicolumn{4}{|l|}{ Clinical symptoms } \\
\hline Bradycardia & $42(87)$ & $9(82)$ & 0,63 \\
\hline Respiratory distress or apnea & $39(81)$ & $11(100)$ & 0,18 \\
\hline Invasive mechanical ventilation & $13(27)$ & $9(82)$ & $<0.0001$ \\
\hline Hyperglycemia & $8,8[6,7-11,6]$ & $10,2[7,6-14,8]$ & 0,19 \\
\hline Vascular Filling & $6 / 48(12,5)$ & $8 / 11(72,7)$ & NA \\
\hline Use of vasopressor & 2 & 11 & $<0.001$ \\
\hline Dobutamine & $0(0)$ & $1(\%)$ & - \\
\hline \multicolumn{4}{|c|}{ LONS, late onset neonatal sepsis; CoNS, coagulase-negative staphylococcus; WBC, white blood cell. } \\
\hline Values are expressed as numbe & dian (IQR). A p & .05 is co & ificant. \\
\hline
\end{tabular}




\begin{tabular}{|c|c|c|c|}
\hline & $\begin{array}{l}\text { Survivors } \\
(n=48)\end{array}$ & $\begin{array}{l}\text { Deceased } \\
(n=11)\end{array}$ & p value \\
\hline Norepinephrine & $2(4)$ & $9(81,8)$ & $<0.001$ \\
\hline Epinephrine & $0(0)$ & $2(18)$ & - \\
\hline \multicolumn{4}{|l|}{ Laboratory findings } \\
\hline Time to positive blood culture (hours) & $11[8-15]$ & $7[5-12]$ & 0,012 \\
\hline Serum lactate $(\mathrm{mmol} / \mathrm{L})[\mathrm{n}=23 / 8]$ & $2[1,8-2,8]$ & $2,25[1,6-2,8]$ & 0,37 \\
\hline WBC $\left(/ \mathrm{mm}^{3}\right)[\mathrm{n}=39 / 11]$ & $8550[6180-13530]$ & $13090[8290-22500]$ & 0,39 \\
\hline Platelets count $\left(/ \mathrm{mm}^{3}\right)[\mathrm{n}=39 / 11]$ & $182[128-220]$ & $104[39-214]$ & 0,11 \\
\hline \multicolumn{4}{|c|}{ LONS, late onset neonatal sepsis; CoNS, coagulase-negative staphylococcus; WBC, white blood cell. } \\
\hline \multicolumn{4}{|c|}{ Values are expressed as number (\%) or median (IQR). A p value $<0.05$ is considered as significant. } \\
\hline
\end{tabular}

Procalcitonin values were significantly higher in deceased patients at $\mathrm{HO}-\mathrm{H} 24$ and $\mathrm{H} 48-\mathrm{H} 72$ (Fig. 1). Accuracy of PCT prognostic value was assessed by calculating AUC-ROC curves. Due to limited number of samples available between $\mathrm{H} 48-\mathrm{H} 72$, only the initial three time points (up to $\mathrm{H} 48$ ) were plotted. At diagnosis (H0), AUC was 0,70 [95\% Cl: $0,49-0,91](p=0,0413)$ for PCT to predict mortality. Optimal threshold value was $8,92 \mu \mathrm{g} / \mathrm{L}$ and was associated with a $63,6 \%[95 \% \mathrm{Cl}: 30,79-89,07]$ sensitivity and a $90,9 \%$ [95\% Cl: 78,33-97,47] specificity (Youden $\mathrm{J}$ index 0.53 ). The proportion of patients with PCT > 8,92 $\mu \mathrm{g} / \mathrm{L}$ in the deceased group was significantly higher $(63,6 \%, 7 / 11)$ than in survivors $(9 \%, 4 / 44)$ (Log rank test $p<0.0001 ; \mathrm{HR} 7.66,95 \% \mathrm{Cl} 1.36-43.09$ ) (Fig. 2A). At H0-H24, the AUC was 0,79 [95\% Cl: 0,56-1,03] $(p=0,0647)$, and optimal cut-off was $15,75 \mu \mathrm{g} / \mathrm{L}$ with a sensitivity of $75 \%$ [95\% $\mathrm{Cl}: 19,41-99,37]$ and a specificity of $81,8 \%$ [95\% Cl: $59,72-94,81$ ] for the 60 days mortality (Youden $\mathrm{J}$ index 0.56 ) (Fig. 2B). At $\mathrm{H} 24-\mathrm{H} 48$, the AUC was 0,8276 [95\% Cl: 0,64-0,1,01] $(p=0,0361)$, with an optimal threshold value at 6.74 $\mu \mathrm{g} / \mathrm{L}$ with a $75 \%$ [95\% Cl: 19,41-99,37] sensitivity and a 79,3\% [95\% Cl: 60,28-92,01] specificity (Youden J index 0.54) (Fig. 2C).

\section{Discussion}

Hereby, we show that PCT has a prognosis value in premature infants with LONS. A PCT value at sepsis diagnostic suspicion higher than $8.92 \mu \mathrm{g} / \mathrm{L}$ has a sensitivity of $63.9 \%$ and specificity of $90.9 \%$ for 60 days mortality. In addition, deceased infants show a significant increase in PCT value from diagnosis to $\mathrm{H} 24-\mathrm{H} 48$.

Late-onset neonatal sepsis is an important cause of death in premature infants and the PCT serum concentration is a valuable tool for early detection of LONS [14]. Majority of LONS occurred primarily in extremely low birth weight (ELBW) infants with a median occurrence time around the third week of 
life $[2,6,7,10]$. In our series, LONS occurred earlier (median post-natal age of 8 days). Similarly, to reported series, CoNS was the predominant pathogen, but Gram-negative bacteria were not rare, with Escherichia coli, Klebsiella spp., Enterobacter cloacae complex. The later was the most frequently encountered pathogen in lethal LONS and may be related to specific virulence of E. cloacae complex [15]. Impact of causative agents on PCT value was not assessed in our study although suggested by others [14].

To our knowledge, no studies have focused on PCT kinetics in LONS. In our study, we showed that PCT values are significantly higher 24 hours after the first clinical symptoms in deceased infants. Multiple studies have shown that the lack of decrease in PCT is associated with mortality in critically ill septic and trauma adults and septic children $[14,16,17,18]$. Cui et al. showed in adults with sepsis and septic shock that on the $2^{\text {nd }}, 3^{\text {rd }}$ and $5^{\text {th }}$ days after diagnosis PCT values were higher in deceased patients compared to survivors [21]. Sakran et al. demonstrated significantly increased mortality among critically ill adults with PCT level $\geq 5 \mu \mathrm{g} / \mathrm{L}$ (odds ratio of 3.65 (95\% Cl 1.23-4.61) [24]. In our study, PCT cut-off value at diagnosis was $8.92 \mu \mathrm{g} / \mathrm{L}$ which is slightly higher. Nevertheless, 9/59 infants (15\%) had PCT level $<0.5$ $\mu \mathrm{g} / \mathrm{L}$ that progressively increased in the following 24 hours. Those "erroneously normal" PCT values may be considered as false negative as all patients of our cohort had microbiologically proven LONS and are certainly resulting from premature sampling. Similarly, Beltempo et al. suggested that optimal timing for biomarkers measurement in VLBW infants with suspected LONS may range between the first 24 hours after diagnosis suspicion [22].

This study has several limitations. First, a lack of power may have occurred due to the small sample size. We have intentionally excluded a significant number of patients (eg. Surgery, necrotizing enterocolitis) with conditions that may significantly affect PCT values and kinetics. Of significance, 21 patients who died within the first five days of LONS were excluded to limit the effect of a survival bias. Second, this study was limited to 60-days mortality and no other prognosis outcome were evaluated. This primary endpoint was set on purpose as we could not exclude delayed mortality considering that LONS are identified risk for long term mortality and morbidity. Duration of antibiotherapy is another recognized prognosis outcome as its impact on the development of multidrug resistance bacteria may strongly impact patients' outcome. Third, as a retrospective study, our results may need to be confirmed in prospective multi-centers cohort to ascertain both the prognostic value of PCT in LONS as well as the identified cut-off values.

In conclusion, we showed that PCT has a prognosis value in premature infants with LONS, with a PCT value $>8.9 \mu \mathrm{g} / \mathrm{L}$ associated with 60-days mortality. In addition, we showed that deceased patients had a significant increase in PCT value between diagnosis and 24-48 hours, suggesting that PCT sampling may be optimal at the time of diagnosis and 24 hours later.

\section{Abbreviations}

CoNS, Coagulase negative Staphylococcus; EONS: Early onset neonatal sepsis; ELBW: Extremely low birth weight; LONS: Late onset neonatal sepsis; NICU: Neonatal intensive care unit; VLBW: Very low birth 
weight.

\section{Declarations}

Funding: No funding

Conflict of interest: Pr. Tissieres reports research grants from Merieux Foundation, bioMerieux Inc., Abionic Inc. outside the submitted work, and consulting fee from bioMerieux, Inotrem. All other authors declare that they have no conflict of interest.

Availability of data and materials: All materials are available upon request to Pr. Pierre Tissières at pierre.tissieres@aphp.fr

Code availability: none

Author's contribution: Design of the work: VR, PT. Acquisition, analysis, or interpretation of data for the work: VR, PT. Drafting the manuscript: VR, PT. Revising it critically for important intellectual content: all authors. All authors approved the final version submitted for publication and agreed to be accountable for all aspects of the work in ensuring that questions related to the accuracy or integrity of any part of the work are appropriately investigated and resolved.

Ethics approval: The study (French study classification: MR004) was approved by the local IRB and French Data Protection Authority (CNIL registration number: 271813) waiving the need of written consent.

Consent to participate: All legal representatives were informed and agreed to participate.

Consent for publication: All authors agreed for publication of this study.

Acknowledgement: none.

Word count body of manuscript: 1630 words

\section{References}

1. Dong Y, Speer CP (2015) Late-onset neonatal sepsis: recent developments. Arch Dis Child Fetal Neonatal Ed 100(3):F257-F263

2. Gowda H, Norton R, White A, Kandasamy Y (2017) Late-onset Neonatal Sepsis-A 10-year Review from North Queensland, Australia. Pediatr Infect Dis J 36(9):883-888

3. Greenberg RG, Kandefer S, Do BT et al (2017) Late-onset Sepsis in Extremely Premature Infants: 2000-2011. Pediatr Infect Dis J 36(8):774-779

4. Stoll BJ, Hansen NI, Bell EF et al (2010) Neonatal outcomes of extremely preterm infants from the NICHD Neonatal Research Network. Pediatrics 126(3):443-456. doi:10.1542/peds.2009-2959 
5. Perlman SE et al (2007) Risk factors for late-onset health care-associated bloodstream infections in patients in neonatal intensive care units. Am J Infect Control vol 35(3):177-182.

doi:10.1016/j.ajic.2006.01.002

6. Tsai MH, Hsu JF, Chu SM et al (2014) Incidence, clinical characteristics and risk factors for adverse outcome in neonates with late-onset sepsis. Pediatr Infect Dis J 33(1):e7-e13

7. Lim WH, Lien R, Huang YC et al (2012) Prevalence and pathogen distribution of neonatal sepsis among very-low-birth-weight infants. Pediatr Neonatol 53(4):228-234.

doi:10.1016/j.pedneo.2012.06.003

8. Nordberg V, Iversen A, Tidell A, Ininbergs K, Giske CG, Navér L. A decade of neonatal sepsis caused by gram-negative bacilli-a retrospective matched cohort study [published online ahead of print, 2021 Mar 24]. Eur J Clin Microbiol Infect Dis. 2021;10.1007/s10096-021-04211-8

9. Stoll BJ, Hansen NI, Adams-Chapman I et al (2004) Neurodevelopmental and growth impairment among extremely low-birth-weight infants with neonatal infection. JAMA 292(19):2357-2365. doi:10.1001/jama.292.19.2357

10. Didier C, Streicher MP, Chognot D et al (2012) Late-onset neonatal infections: incidences and pathogens in the era of antenatal antibiotics. Eur J Pediatr 171(4):681-687. doi:10.1007/s00431011-1639-7

11. Jacquot A, Labaune JM, Baum TP, Putet G, Picaud JC (2009) Rapid quantitative procalcitonin measurement to diagnose nosocomial infections in newborn infants. Arch Dis Child Fetal Neonatal Ed 94(5):F345-F348

12. Vouloumanou EK, Plessa E, Karageorgopoulos DE, Mantadakis E, Falagas ME (2011) Serum procalcitonin as a diagnostic marker for neonatal sepsis: a systematic review and meta-analysis. Intensive Care Med 37(5):747-762

13. Yu Z, Liu J, Sun Q, Qiu Y, Han S, Guo X (2010) The accuracy of the procalcitonin test for the diagnosis of neonatal sepsis: a metaanalysis. Scand J Infect Dis 42:723-733

14. AlRawahi AN, AlHinai FA, Doig CJ et al (2019) The prognostic value of serum procalcitonin measurements in critically injured patients: a systematic review. Crit Care 23(1):390. doi:10.1186/s13054-019-2669-1 Published 2019 Dec 3.

15. Luis A, Augusto, Nadège Bourgeois-Nicolaos, A, Breton S, Barreault, Enrique Hernandez Alonso, Stuti Gera, Véronique Faraut-Derouin, Nada Semaan, Daniele De Luca, Richard Chaby, Florence DoucetPopulaire, Pierre Tissières. Presence of 2-hydroxymyristate on endotoxins is associated with death in neonates with Enterobacter cloacae septic shock. iScience 2021, 102916. https://doi.org/10.1016/j.isci.2021.102916

16. Harbarth S, Holeckova K, Froidevaux C, Pittet D, Ricou B, Grau GE, Vadas L, Pugin J; Geneva Sepsis Network. Diagnostic value of procalcitonin, interleukin-6, and interleukin-8 in critically ill patients admitted with suspected sepsis. Am J Respir Crit Care Med (2001) Aug 1;164(3):396-402. doi: 10.1164/ajrccm.164.3.2009052. PMID: 11500339 
17. Pieralli F, Vannucchi V, Mancini A, Antonielli E, Luise F, Sammicheli L, Turchi V, Para O, Bacci F, Nozzoli C (2015 Sep) Procalcitonin Kinetics in the First 72 Hours Predicts 30-Day Mortality in Severely III Septic Patients Admitted to an Intermediate Care Unit. J Clin Med Res 7(9):706-713. doi:10.14740/jocmr2251w. Epub 2015 Jul 24. PMID: 26251686; PMCID: PMC4522989

18. Poddar B, Gurjar M, Singh S, Aggarwal A, Singh R, Azim A, Baronia A (2015 Mar) Procalcitonin kinetics as a prognostic marker in severe sepsis/septic shock. Indian J Crit Care Med 19(3):140-146. doi:10.4103/0972-5229.152755. PMID: 25810608; PMCID: PMC4366911

19. Fendler WM, Piotrowski AJ (2008) Procalcitonin in the early diagnosis of nosocomial sepsis in preterm neonates. J Paediatr Child Health 44(3):114-118. doi:10.1111/j.1440-1754.2007.01230.x

20. Assicot M, Gendrel D, Carsin H, Raymond J, Guilbaud J, Bohuon C (1993) High serum procalcitonin concentrations in patients with sepsis and infection. Lancet 341(8844):515-518. doi:10.1016/01406736(93)90277-n

21. Cui N, Zhang H, Chen Z, Yu Z (2019) Prognostic significance of PCT and CRP evaluation for adult ICU patients with sepsis and septic shock: retrospective analysis of 59 cases. J Int Med Res 47(4):1573-1579. doi:10.1177/0300060518822404

22. Beltempo $M$, Viel-Thériault I, Thibeault $R$, Julien AS, Piedboeuf B. C-reactive protein for late-onset sepsis diagnosis in very low birth weight infants. BMC Pediatr. 2018;18(1):16. Published $2018 \mathrm{Jan}$ 30. doi:10.1186/s12887-018-1002-5

23. Aydemir C, Aydemir H, Kokturk F, Kulah C, Mungan AG. The cut-off levels of procalcitonin and Creactive protein and the kinetics of mean platelet volume in preterm neonates with sepsis. $B M C$ Pediatr. 2018;18(1):253. Published 2018 Aug 1. doi:10.1186/s12887-018-1236-2

24. Sakran JV, Michetti CP, Sheridan MJ et al (2012) The utility of procalcitonin in critically ill trauma patients. J Trauma Acute Care Surg 73(2):413-418. doi:10.1097/TA.0b013e31825ff5b7

25. Neunhoeffer F, Plinke S, Renk $\mathrm{H}$ et al Serum Concentrations of Interleukin-6, Procalcitonin, and Protein C-Reactive: Discrimination of Septical Complications and Systemic Inflammatory Response Syndrome after Pediatric Surgery. Eur J Pediatr Surg. 2016;26(2):180-185. doi:10.1055/s-00341544047

26. Horan TC, Andrus M, Dudeck MA (2008 Nov;36(9):655) CDC/NHSN surveillance definition of health care-associated infection and criteria for specific types of infections in the acute care setting. Am J Infect Control. 2008 Jun;36(5):309 - 32. doi: 10.1016/j.ajic.2008.03.002. Erratum in: Am J Infect Control. PMID: 18538699

\section{Figures}


< 32 weeks of GA hospitalized in NICU between january 2015 and december 2018

$n=689$

No Health associated Infection $(n=438)$

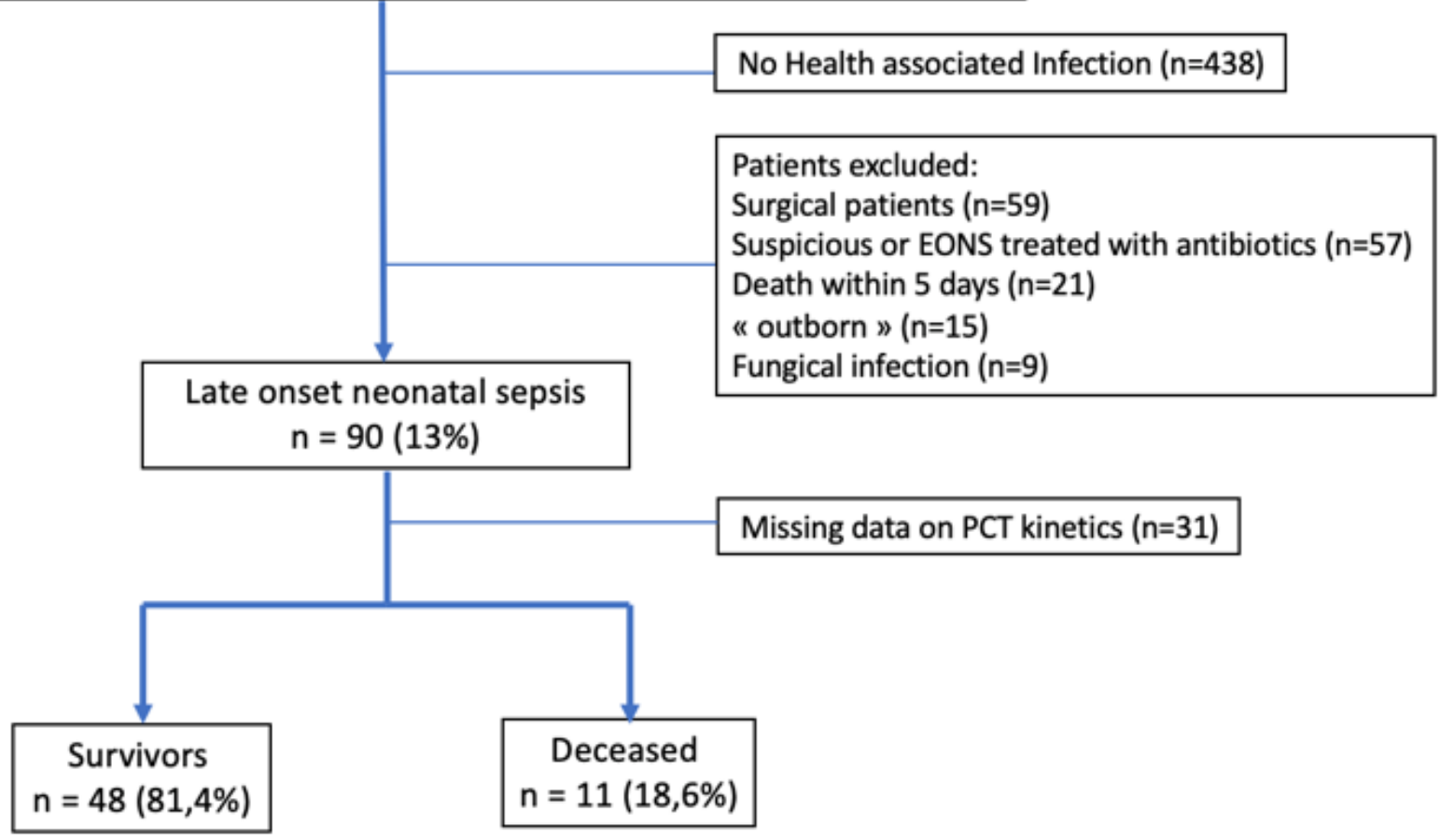

Figure 1

Flow Chart 


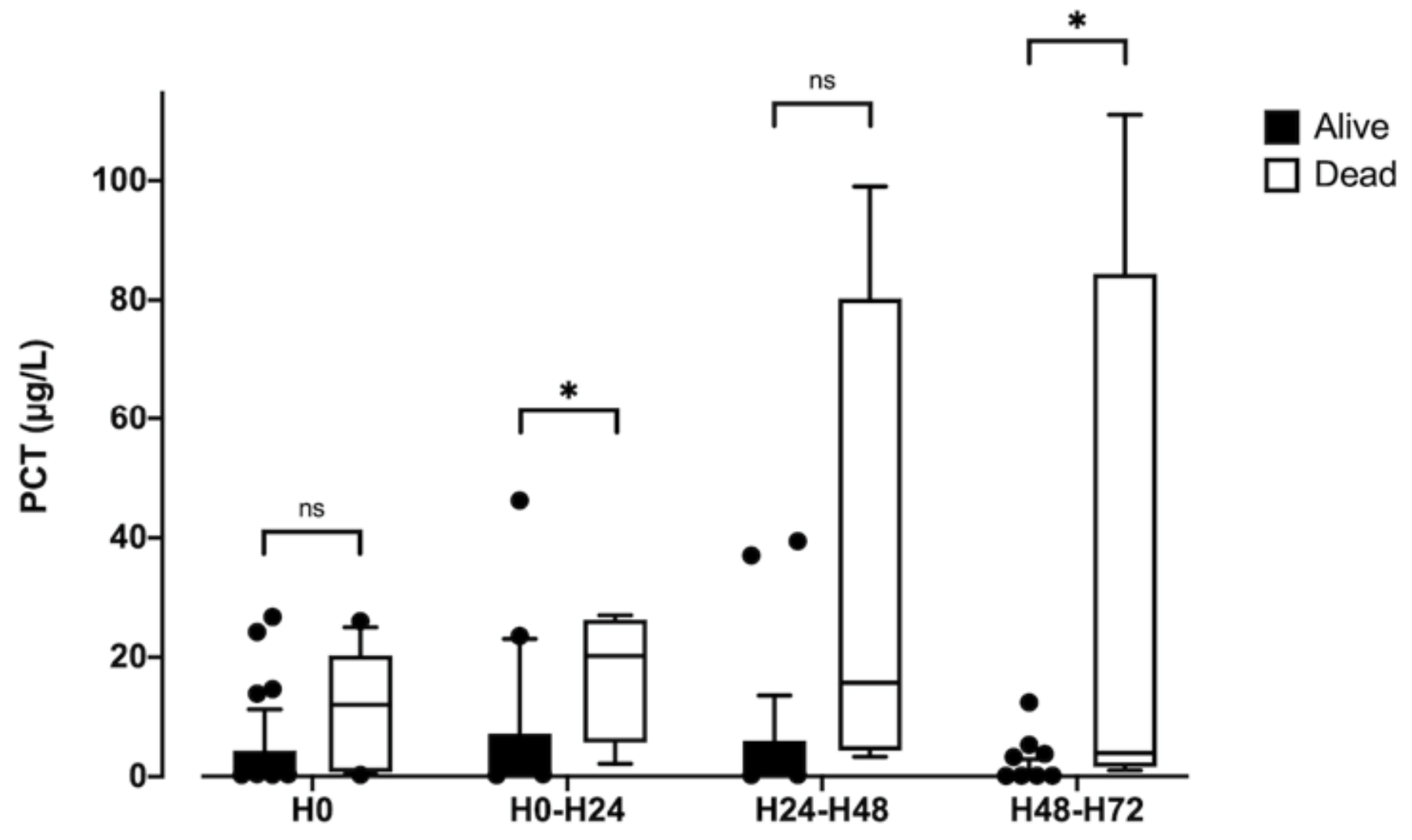

Figure 2

Procalcitonin (PCT) kinetics during the first 72 hours following late onset neonatal sepsis (LONS) diagnosis. PCT values at diagnosis $(\mathrm{H} 0)$, during the first day $(\mathrm{H} 0-\mathrm{H} 24)$, during the second day $(\mathrm{H} 24-\mathrm{H} 48)$ and third day (H48-H72) in survivors (black) and deceased infants (white). ${ }^{*} p<0,05 ; n s$, non significant. 
A

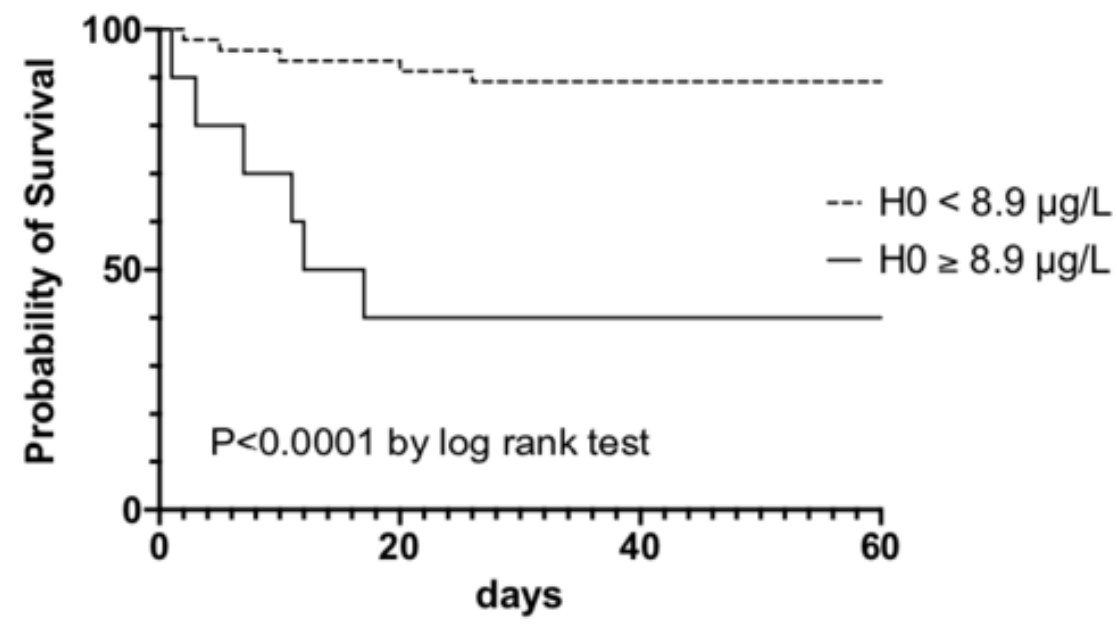

B

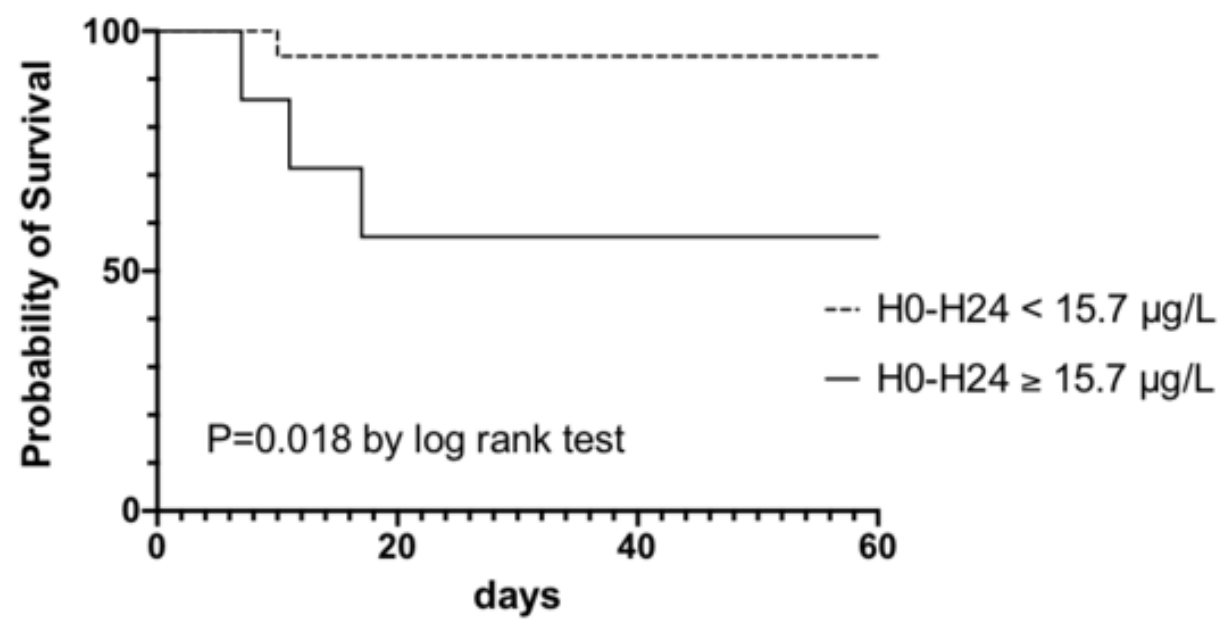

C

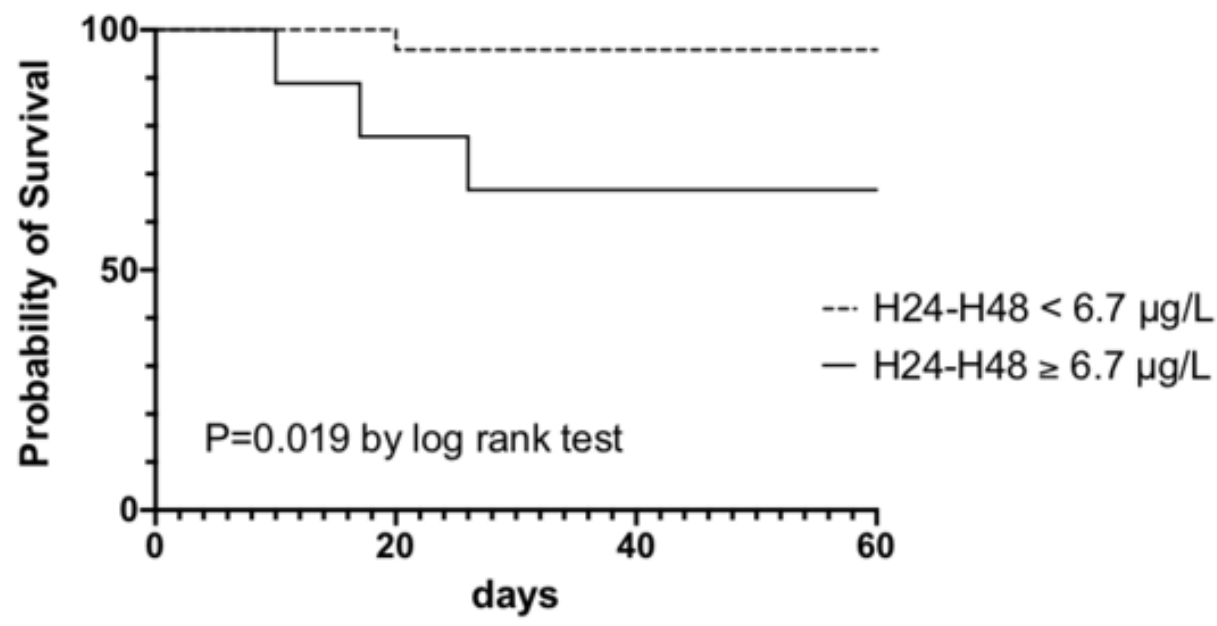

Figure 3

Kaplan-Meier Survival curve 